\title{
Smart Specialisation for Economic Change: The Case of Spain
}

\author{
Jaime del Castillo $^{*}$, Jonatan Paton ${ }^{* *}$, Belen Barroeta ${ }^{* * *}$
}

\begin{abstract}
Smart specialisation concept acquired a remarkable importance in the current regional policy as a model to understand the role of territories in international competitiveness. In fact, the definition of Smart Specialisation Strategies (RIS3) has become an ex ante conditionality for European regional policy in the period 20142020. Although the process of definition has been a good opportunity to rethink and improve the policymaking, it has not been out of difficulties and barriers since it is not always easy to translate academic concepts to real policies in the field. These difficulties are analysed from a threefold perspective: the definition, implementation and evaluation of RIS3. These three aspects are seen in the recently finished Spanish RIS3, with specific attention to: priority setting, policy instruments, and evaluation.
\end{abstract}

Keywords: Smart Specialisation; Smart Specialisation Strategies; RIS3 in Spain; Global Competition; Global Markets

\section{The Research Questions}

Recently a territorial development model has arisen focused on territorial search of specialized diversification. This model, known as smart specialization, is achieving remarkable relevance in the current postulates of European Regional Policy to the point of becoming, through the development of a strategy for smart specialization, an ex-ante condition for the Structural Funds in 2014-2020.

In this context, European regions carried out a process of definition of these strategies that ended recently with the beginning of the new programming period. These processes accounted for a number of difficulties and limitations that will inevitably determine the success of the implementation stage.

The objective of this paper is to analyse these risks and assess the starting point of the implementation stage of the Regional Innovation Smart Specialisation

\footnotetext{
* Full Professor of Applied Economics, University of Basque Country (infyde@infyde.eu)

** PhD Researcher, INFYDE (jonatanpaton@infyde.eu)

*** CEO, INFYDE (belenbarroeta@infyde.eu)
}

Edited by: ISTEI - University of Milan-Bicocca

ISSN: 1593-0319

del Castillo Jaime, Paton Jonatan, Barroeta Belen (2015) Smart Specialisation for Economic Change: The Case of Spain, Symphonya. Emerging Issues in Management (symphonya.unimib.it), n. 1 , pp. $30-43$. 
Strategies (RIS3) for the case of Spanish regions. More specifically, the research questions proposed are the following:

- Do the priorities chosen in the RIS3 strategies represent the real territorial specialisation patterns?

- What kind of policy objectives have the Strategies included?

- What kind of policy instruments have the Strategies included for implementation?

- Do the evaluation, monitoring and governance process reflect the postulated proposed by EC?

- What are the main conclusions regarding RIS3 versus RIS Strategies?

\section{Theoretical Issues and Policy Implications}

\subsection{Smart Specialisation: the Core of the Concept}

The concept of smart specialization comes from reflection generated around the structural gap between Europe and the USA (Pontikakis et al. 2009), as result of a lower economic and technological specialization and less ability to prioritize and to dedicate consistent efforts at the regional level.

Smart specialization is a territorial development model initiated mainly by authors that currently advise the Commission itself (Foray et al., 2009, Foray 2009a and McCann and Ortega-Argilés 2011). It can be summarized as "the prioritizing that takes place at a territorial level in economic activities, scientific areas and technological domains that are potentially competitive and generators of new market opportunities in a global context versus the prioritizing that other territories carry out" (Del Castillo et al. 2012). According to all these authors, the concept can be broken down into three main elements, namely:

- The prioritization in a limited number of areas (technological domains, scientific areas and economic activities) where the region is competitive.

- The search for opportunities through the exploitation of the territorial related variety, maximizing its externalities and generating new business activities through entrepreneurial discoveries.

- The coherence of the whole process within the global context, where territorial specialization is part of a global value chain and regarding the choices of other regions.

Nevertheless, against the extended thinking, smart specialization goes beyond the mere prioritization of a limited number of economic niches to a deeper diversification from what a territory is specialised: a search for specialised diversification (Del Castillo et al. 2015a).

It is, in fact, the traditional dilemma about what kind of agglomeration economies to exploit (Frenken et al. 2007): location economies (promoting sectorial specialization); urbanization economies (promoting sectorial diversification) or related variety exploitation (finding a balance between the above two above). In this context, a strategy for smart specialization may focus on seeking specialized diversification behind the related variety of a given territory.

Therefore, the processes for elaborating a RIS3 not only may encounter difficulties in terms of how to identify and prioritize these opportunity niches of 
specialised diversification, but also in terms of how to design and implement the appropriate measures to support them (Del Castillo et al. 2013a) as well as to monitor them (Del Castillo et al. 2015b).

\subsection{Smart Specialisation and RIS3}

Smart specialisation has been established as one of the conditions for accessing the ERDF in this programming period $2014-2020$ in the shape of RIS3 (EC 2013 and EC 2011). The EC has oriented the elaboration of these strategies with the support by IPTS and its S3 Platform ${ }^{1}$, mainly with a guide divided in six stages (IPTS 2012) and a number of thematic reports ${ }^{2}$.

Nevertheless, RIS3 process is not a completely new approach compared to them innovation strategic experiences observed since the 90s in Europe (RIS, RITTS and RTP) aimed at strengthening innovation systems and at increasing their contribution to regional development (Bellini et al. 2012, OECD 2011, Technopolis 2006, EC 2002). Del Castillo et al. (2013a) identified on both (these old strategies and the current RIS3) a common set of elements intrinsic to strategic planning: reflection, prioritization, consensus, monitoring its implementation.

Table 1: RIS3 Elaboration Stages Regarding a Common Process of Policy Planning

\begin{tabular}{|c|c|c|}
\hline ELEMENTS & IMPLICATION IN TERMS OF RIS3 & KEY ASPECTS \\
\hline $\begin{array}{l}\text { Reflection and } \\
\text { definition } \\
(2011-2014) *\end{array}$ & $\begin{array}{l}\text { There must be a strategic reflection regarding the prior areas in } \\
\text { economic, scientific and technological terms; the kind of governance } \\
\text { that will assure entrepreneurial discovery through the process } \\
\text { (quadruple helix); the implementation tools and finally the } \\
\text { mechanisms to guarantee a revision of the strategy and } \\
\text { improvement. }\end{array}$ & $\begin{array}{l}\text { - Priority setting } \\
\text { - SWOT definition } \\
\text { - Participatory governance } \\
\text { - Entrepreneurial discovery } \\
\text { - Measures and policies }\end{array}$ \\
\hline $\begin{array}{l}\text { Implementation } \\
(2015-2020)^{*}\end{array}$ & $\begin{array}{l}\text { During the lifetime of the strategy, the tools and procedures } \\
\text { developed in the first stage must be continuously implemented and } \\
\text { improved. Specifically it is critical to maintain the governance } \\
\text { mechanism that identifies entrepreneurial discovery processes and } \\
\text { initiatives that generate wealth and employment. }\end{array}$ & $\begin{array}{l}\text { - Participatory governance } \\
\text { - Entrepreneurial discovery } \\
\text { - Action Plan implementation } \\
\text { - Strategy improvement }\end{array}$ \\
\hline $\begin{array}{l}\text { Monitoring and } \\
\text { evaluation } \\
(2015-2022)^{*}\end{array}$ & $\begin{array}{l}\text { The monitoring of the strategy is a mechanism that ensures } \\
\text { continuous improvement, efficiency and effectiveness. As part of } \\
\text { this need, there must be indicators to provide the necessary } \\
\text { information so that there is a periodic improvement a refocusing of } \\
\text { the strategy. }\end{array}$ & $\begin{array}{l}\text { - Intervention logic } \\
\text { - Indicators (output \& result) } \\
\text { - Monitoring system }\end{array}$ \\
\hline
\end{tabular}

*Indicative periods

Source: Del Castillo et al. (2013a)

Leaving aside all the conceptual and theoretical schemes that have enriched exceedingly both smart specialization model and RIS3, and taking as premises all those items mentioned previously, what is really important to know is how to extend and systematize processes of specialised diversification (through the so called entrepreneurial discovery) at regional level. Accordingly, as Paton (2013) considers, a RIS3 process may characterized by: 
- how to generate the methodological foundations to a good analysis of regional competitiveness,

- how to identify entrepreneurial discovery initiatives,

- how to reach consensus and commitments about actions and instruments to support these initiatives among all agents involved and,

- how to ensure that these channels are not conjunctural elements linked to the elaboration of a document, but part of a wider process that also includes the implementation and monitoring.

\subsection{Problems and Barriers Encountered during the Process of RIS3}

Due to the popularization of the concept in the academic literature as well as the novelty of the exercise on defining the RIS3, it is not easy to find references on critical approaches about the difficulties and barriers when defining, implementing and monitoring such strategies. However, Paton and Barroeta (2012) mention a number of them making clear that besides the many opportunities behind smart specialisation, there is also a significant number of risks to consider.

Table 2: Opportunities and Risks Regarding Main Elements of Smart Specialisation

\begin{tabular}{|c|c|c|}
\hline ELEMENTS & OPPORTUNITIES & RISKS \\
\hline $\begin{array}{l}\text { Prioritization } \\
\text { Election of } \\
\text { priorities through } \\
\text { specialisation } \\
\text { patterns }\end{array}$ & $\begin{array}{l}\text { - To prioritize can help creating critical } \\
\text { mass to achieve excellence. } \\
\text { - Prioritizing the demands of the } \\
\text { businesses facilitates the alignment of } \\
\text { the regional capabilities with the } \\
\text { market opportunities. }\end{array}$ & $\begin{array}{l}\text { - Not all regions find themselves at the same starting } \\
\text { point in terms of entrepreneurial capability, sometimes } \\
\text { resulting in the creation of bigger gaps. } \\
\text { - Reaching a critical mass and sufficient excellence in } \\
\text { R\&D to match the supply and demand is complicated. } \\
\text { - Intermediary infrastructure must play a proactive role, } \\
\text { although the reality does not always allows it. }\end{array}$ \\
\hline $\begin{array}{l}\text { Specialised } \\
\text { diversification } \\
\text { Exploitation of } \\
\text { regional related } \\
\text { variety }\end{array}$ & $\begin{array}{l}\text { - Take into account that the horizontal } \\
\text { specialization will contribute to the rest } \\
\text { of the economy (knock-on effects) } \\
\text { - Exploiting the possibilities of regional } \\
\text { related diversity can lead to radical } \\
\text { innovation and "rethinking" of the } \\
\text { economy. }\end{array}$ & $\begin{array}{l}\text { - A high specialization also brings further weakness to } \\
\text { potential crisis, technical changes and cycles. } \\
\text { - It is difficult to identify the entrepreneurial discovery } \\
\text { (no clear methodologies for it). } \\
\text { - If there is no entrepreneurial critical mass, social } \\
\text { capital, no experience of the authorities, etc., the } \\
\text { governance of the process may be unworkable. }\end{array}$ \\
\hline $\begin{array}{l}\text { Global context } \\
\text { Coherence of } \\
\text { priorities and the } \\
\text { process in the } \\
\text { frame of an open } \\
\text { economy }\end{array}$ & $\begin{array}{l}\text { - A "global" dimension of governance } \\
\text { will allow the prioritized specialization } \\
\text { to be consistent in the global context. } \\
\text { - To define the specialization in terms of } \\
\text { a global value chain multiplies its } \\
\text { chances of success. }\end{array}$ & $\begin{array}{l}\text { - Certain types of knowledge can only be developed by a } \\
\text { number of advanced regions, and therefore the co- } \\
\text { inventor and follower regions and may experience an } \\
\text { uneven "trade-off". } \\
\text { - Many internal and external dimensions not always } \\
\text { controllable influence results of smart specialization. } \\
\text { - The approach of governance in an open economy is } \\
\text { still not widespread although its success depends on its } \\
\text { ability to generate interregional cooperation. }\end{array}$ \\
\hline
\end{tabular}

Source: Paton \& Barroeta (2012)

Nevertheless, these aspects addressed by Paton and Barroeta (2012) only reflects the general conceptual limitations of the smart specialisation concept. With the 
beginning of the definition exercises by policymakers between 2013 and 2014, a number of difficulties have arisen (Paton 2013):

- First, despite the lengthy theoretical literature on smart specialization, there is a certain lack on practical guidelines from real policy experimentation on the field. ${ }^{3}$

- Second, the latter statement is even more obvious when referring to entrepreneurial discovery, a fuzzy concept with a lack of real examples that, on the contrary, appears as the core element to achieve specialized diversification processes.

- Third and finally, the link among the RIS3 and the ex-ante condition of the Structural Funds put high pressure on the deadlines to have them defined and launched (even though this pressure did not correspond to what in theory would be required for an effective and appropriate definition of this kind of strategies).

As mentioned in the research questions section, these opportunities and risks, as well as the real difficulties and problems encountered by policymakers when defining the RIS3, have inevitably determined the quality and usefulness of not only the documents but also the processes themselves. In this paper, we have considered the Spanish regional approach to RIS3 as a good example to analyse these issues since these regions have been proactive and diverse in the way they tackle the process ${ }^{4}$.

\section{The Spanish Case: the State of the Art}

In this section of the paper, the main aspects of a RIS3 described before have been analysed in the Spanish strategies. Specifically, we have analysed three aspects that focused the attention of policymakers:

- the priority setting and the entrepreneurial discovery,

- the policy mix (or RIS3 actions plans) and

- the evaluation and monitoring.

The research has combined a twofold approach: a first one focused on a quantitative analysis to compare the specialisation priorities included in the Spanish RIS3 to the "real" (statistical) territorial specialisation pattern obtained by using economic agglomeration mapping methodologies. A second one focused on a qualitative analysis to gather information about policy objectives and measures, monitoring and evaluation systems as well as the governance mechanism included for the implementation stage until 2020.

Table 3: Research Methodology

\begin{tabular}{|l|l|l|}
\hline \multicolumn{1}{|c|}{ APPROACH } & \multicolumn{1}{|c|}{ DATA } & \multicolumn{1}{c|}{ METHOD } \\
\hline \multirow{3}{*}{ Quantitative } & $\begin{array}{l}\text { Statistical data from Spanish National Statistics } \\
\text { Institute (INE) on number of establishments, GDP, } \\
\text { employment and Input-Output regional economic } \\
\text { accounts (www.ine.es). }\end{array}$ & $\begin{array}{l}\text { Specialisation pattern mapping following Del } \\
\text { Castillo and Paton (2011 and 2013b), Paton } \\
\text { (2014), MacCann and Ortega Argiles (2011) and } \\
\text { Frenken et al. (2007). }\end{array}$ \\
\hline
\end{tabular}




\begin{tabular}{|l|l|l|}
\hline \multirow{4}{*}{ Qualitative } & $\begin{array}{l}\text { Qualitative data: all the regional RIS3 in Spain } \\
\text { available from the Spanish Ministry of Finance } \\
\text { and Public Administration (MINHAP) }\end{array}$ & $\begin{array}{l}\text { Benchmarking analysis on priority setting, } \\
\text { policy objectives and measures, monitoring and } \\
\text { evaluation systems. }\end{array}$ \\
$\begin{array}{l}\text { (http://www.dgfc.sgpg.meh.es/sitios/dgfc/) and } \\
\text { each regional website for smart specialisation. }\end{array}$ & \\
\hline
\end{tabular}

Source: Paton \& Barroeta (2012)

\subsection{The Priority Setting in RIS3: Specialisation, Technology and Entrepreneurial Discoveries}

One of the main issues of discussion during the RIS3 definition phase was about how to identify and prioritize specialisation areas (both economic and scientifictechnological). Furthermore, how to identify and support the flowering of entrepreneurial discovery processes (Foray 2009b) and projects (Del Castillo 2015a). Even though the latter has no practical guidelines ${ }^{5}$ further than specific case studies (Del Castillo et al. 2015a), the first characterised by the extended use of (cluster) mapping exercises and the use of some metrics such as the specialisation coefficient (SC) ${ }^{6}$.

Table 4: Regions in Spain by Type of Economic Priority Included in the RIS3 2014-2020

\begin{tabular}{|c|c|c|c|c|c|c|c|c|c|c|c|c|c|c|c|c|c|}
\hline & 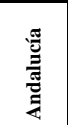 & $\begin{array}{l}\text { 总 } \\
\text { 焉 }\end{array}$ & 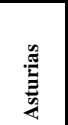 & 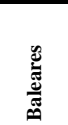 & 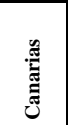 & 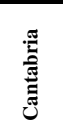 & 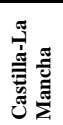 & 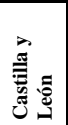 & 䒿 & ن & 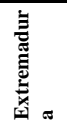 & 吾 & 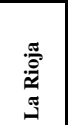 & 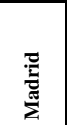 & 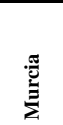 & 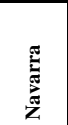 & 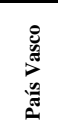 \\
\hline Agroindustry & 124,4 & 122,8 & 107,7 & 62,9 & 68,3 & 88,4 & 204,5 & 201,0 & 68,1 & 65,0 & 231,3 & 118,3 & 337,4 & 32,6 & 130,7 & 185,8 & 99,3 \\
\hline Sea activities & 78,6 & 57,0 & 127,3 & 0,0 & 35,8 & 931,6 & 40,9 & 42,3 & 48,9 & 94,2 & 36,4 & 392,3 & 98,5 & 37,3 & 95,4 & 84,1 & 218,7 \\
\hline Textile and fashion industry & 68,0 & 94,3 & 38,8 & 61,1 & 18,5 & 30,3 & 150,0 & 54,5 & 134,5 & 253,5 & 29,5 & 87,6 & 288,2 & 58,9 & 87,5 & 54,7 & 47,9 \\
\hline Chemical industry & 83,8 & 115,5 & 57,6 & 32,8 & 38,1 & 66,0 & 119,8 & 53,3 & 155,5 & 143,8 & 77,7 & 60,4 & 152,8 & 72,7 & 156,7 & 97,8 & 98,5 \\
\hline Metal manufacturing & 82,2 & 133,2 & $\mathbf{9 4 , 7}$ & 60,1 & 49,1 & 104,3 & 152,0 & 105,5 & 114,5 & 87,5 & 107,5 & 89,3 & 130,4 & 65,3 & 91,0 & 166,3 & 218,7 \\
\hline Machinery and equipment & 49,9 & 195,8 & 58,2 & 17,5 & 9,5 & 74,8 & 90,4 & 88,0 & 159,7 & 112,2 & 34,8 & 66,5 & 160,5 & 59,2 & 133,7 & 206,3 & 251,0 \\
\hline ICT and electronic devices & 58,2 & 81,5 & 62,2 & 75,1 & 56,7 & 58,4 & 40,3 & 49,9 & 131,8 & 83,0 & 41,5 & 58,0 & 57,3 & 218,2 & 58,0 & 74,3 & 117,9 \\
\hline Automotive industry & 65,3 & 273,2 & 92,3 & 9,8 & 32,4 & 69,7 & 148,2 & 143,1 & 119,1 & 70,8 & 79,2 & 88,9 & 205,2 & 61,6 & 124,5 & 441,9 & 147,1 \\
\hline Aerospace industry & 137,3 & 224,6 & 0,0 & 0,0 & 31,7 & 0,0 & 257,7 & 100,0 & 0,0 & 0,0 & 64,6 & 61,4 & 174,6 & 146,1 & 0,0 & 0,0 & 525,5 \\
\hline Naval industry & 107,2 & 0,0 & 141,0 & 212,1 & 49,5 & 81,9 & 16,8 & 6,5 & 80,6 & 91,7 & 0,0 & 447,2 & 0,0 & 21,4 & 129,2 & 0,0 & 201,9 \\
\hline Energy generation and distribution & 62,5 & 186,0 & 84,3 & 25,9 & 34,3 & 92,3 & 123,1 & 157,6 & 108,9 & 117,9 & 95,6 & 65,9 & 118,8 & 87,2 & 110,2 & 222,7 & 161,2 \\
\hline Habitat & 101,8 & 112,0 & 87,9 & 95,5 & $\mathbf{5 0 , 8}$ & 95,5 & 169,7 & 117,6 & 85,6 & 128,5 & 128,1 & 124,1 & 165,4 & 50,5 & 147,8 & 136,1 & 108,3 \\
\hline Construction & 92,9 & 109,2 & 92,2 & 119,7 & 74,2 & 109,0 & 137,5 & 124,5 & 93,7 & 94,5 & 131,9 & 116,6 & 98,7 & 87,4 & 107,6 & 104,6 & 104,0 \\
\hline Water management & 124,1 & 265,0 & 23,5 & 93,4 & 225,0 & 26,3 & 84,3 & 55,0 & 54,2 & 238,0 & 84,5 & 13,1 & 150,6 & 24,1 & 257,4 & 193,6 & 26,5 \\
\hline Recycling activities & 94,7 & 113,3 & 74,2 & 88,7 & 88,0 & 170,5 & 124,6 & 123,3 & 96,1 & 83,4 & 106,8 & 96,9 & 102,8 & 82,4 & 98,6 & 172,7 & 155,7 \\
\hline Transport and logistic activities & 111,7 & 97,2 & 114,6 & 87,0 & 153,3 & 107,4 & 124,6 & 102,7 & 88,1 & 83,0 & 96,9 & 103,6 & 66,4 & 98,1 & 107,0 & 99,1 & 80,4 \\
\hline Tourism activities & 110,4 & 99,8 & 133,6 & 138,1 & 137,9 & 125,6 & 88,7 & 114,0 & 90,8 & 100,7 & 95,9 & 109,9 & 104,9 & 74,1 & 93,1 & 84,3 & 91,8 \\
\hline Experience activities & 99,4 & 98,0 & 119,5 & 114,2 & 115,0 & 94,8 & 81,2 & $\mathbf{9 4 , 7}$ & 93,5 & 96,9 & 108,0 & 96,8 & 101,4 & 117,5 & 85,1 & 94,5 & 87,0 \\
\hline Health industry & 34,7 & 128,7 & 71,0 & 48,5 & 21,4 & 17,7 & 65,2 & 84,2 & 232,4 & 36,8 & 0,0 & 41,4 & 29,4 & 164,6 & 68,4 & 134,0 & 75,9 \\
\hline Wellness activities & 101,6 & 97,3 & 108,0 & 80,5 & 94,6 & 102,8 & 74,2 & 96,4 & 99,7 & 94,4 & 92,3 & 95,9 & 84,4 & 116,2 & 92,3 & 90,6 & 116,6 \\
\hline
\end{tabular}

Notes:

- Sectors with values above $110 \%$ are considered as specialised (from Paton 2014)

- Grey squares represent the critical mass identified by the application of specialisation coefficients (SC) in each region

- Red marked values represent sectors considered priorities in RIS3 but with no critical mass according to SC 
- Blue marked values represent sectors not considered priorities in RIS3 but with critical mass according to $\mathrm{SC}$

Source: INFYDE 2015

Following the methodology popularised by Porter (2003) and extended by Cluster Observatory $^{7}$, we have obtained the SC of Spanish regions by a number of economic sectors covered in the RIS3. We have checked also if the value for each $\mathrm{SC}$ in each region is coherent to the prioritization made in the corresponding RIS3. The results of this analysis can be observed in Table 4 with a detailed breakdown by economic sector (rows) and region (columns). Specifically:

- those sectors identified as specialised regarding the Spanish average (grey squares),

- those sectors identified as specialised but not considered as priorities in RIS3 (marked in blue),

- those sectors not identified as specialised but considered as priorities in RIS3 (marked in red).

According to the figures in Table 4, in general terms it can be noted that the priority setting has been relatively lax, at least regarding the total number of sectors considered by region. In fact, the limitation on what to include in the strategy usually encounters opposition by lobbies and groups of interest, as well as the fear from authorities to excessively limit the choices for such a long period (20142020). Other interesting conclusions can be summarised regarding the priority setting in Spanish RIS3:

- Sectors identified as specialised by the SC are lower in number than those included in the RIS3.

- There is no a clear economic justification of a wider selection of sectors beyond the risk aversion of authorities on the choosing process of priorities ${ }^{8}$.

- RIS3 seems to have prioritized sectors with a very clear share in total economy (agro industry, automotive, tourism and experience) and others with positive international trends (energy, eco industries, health and wellness and ICT).

- Sectors where regions have a clear specialisation degree are similar in some cases to those in RIS3 (e.g. agro industry, environmental-eco industries and tourism with high degree of specialisation and included in RIS3) but not in others (e.g. metal manufacturing and machinery equipment with high degree of specialisation but no included in RIS3, and the contrary for health and wellness).

A similar analysis has been carried out for the technological priorities considered in the Spanish RIS3. They has been grouped in general technological domains know as Key Enabling Technologies (KETs) by the Commission (2009) ${ }^{9}$.

As shown in Figure 1, Spanish RIS3 seem to have prioritized technological domains of ICT and biotechnology mainly, followed by others such as advanced manufacturing and advanced materials. Nanotechnologies and photonics (this is usually included under ICT section) are not so commonly included in the Strategies, and microelectronics seems to be the least chosen. Finally, in terms of technological domains per region, on average between 4/5 domains have been selected. These figures reflect therefore a lack of technological specialisation 
among regions, although a further analysis considering specific technologies (no wider domains) must be done.

Figure 1: Regions in Spain by Type of Technological Priority Included in the RIS3 2014-2020
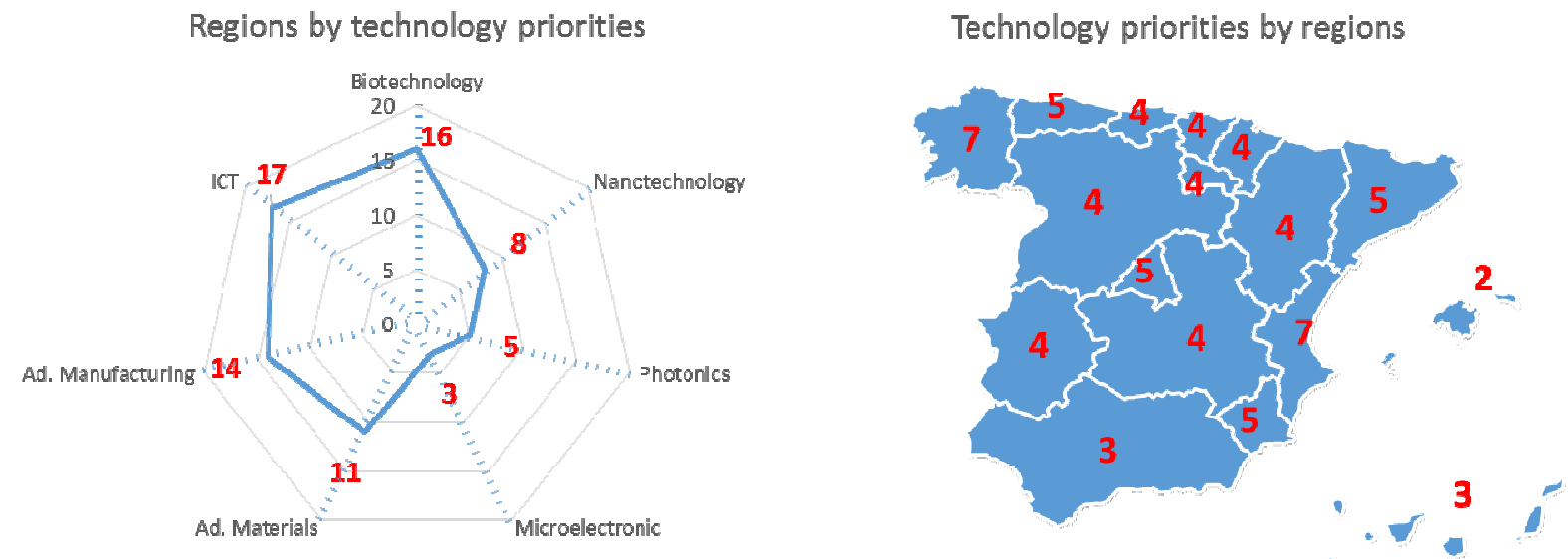

Source: INFYDE 2015

Finally, regarding the entrepreneurial discovery process, although it has been included in many RIS3 under the participatory governance process (e.g. workshops, seminar, etc.) there were not included specific examples or projects that reflect their existence in the regions. As Del Castillo et al. (2015a) noted, it can be considered as a consequence of a tough concept with a lack of applied techniques and proposals to be identified or supported at regional level by policymaking. Nevertheless, it may be mentioned that some Strategies have included specific instruments devoted to develop both processes and project of entrepreneurial discoveries (see 3.2).

\subsection{The Operational Plans in RIS3: Actions and Policy Instruments}

The second area analysed in Spanish RIS3 has been the policy approach both in terms of general objectives and specific measures and instruments. Regarding the first, Spanish regions seem to have been quite traditional in terms of policy objectives: education/training, and internationalisation seem to be the two main axes considered repeatedly, followed by traditional S\&T support and overall business competitiveness. Besides, among the Spanish regional objectives appears also the entrepreneurial promotion (and specifically the search for entrepreneurial discoveries) as well as the networking and cooperation within the triple helix (including measures to promote clusters). 
Figure 2: Number of regions in Spain by Type of Policy Area Included in the RIS3 2014-2020

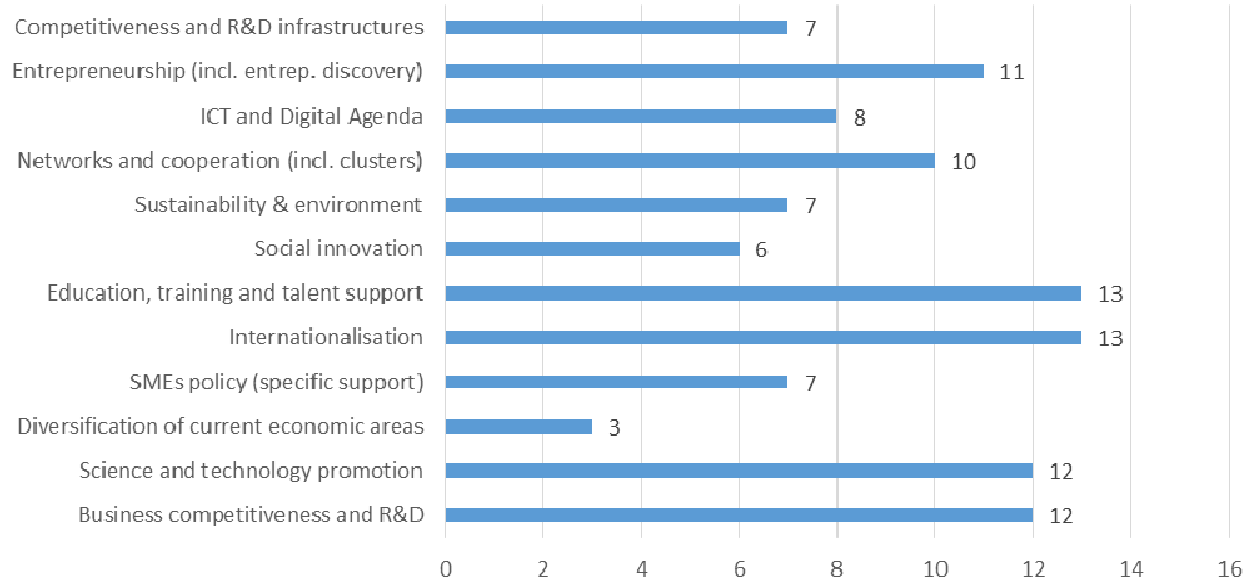

Source: INFYDE 2015

However, regarding the concrete policy instruments, it can be observed a shift between the traditional financial support (grant) to non-financial support (services provided by intermediate infrastructures, competitive intelligence, networks, etc.) or even reimbursement finance (loans, micro credits, venture capital, etc.).

The most repeated instruments in the RIS3 analysis are grants (a traditional support framework in Spain), network and platforms for collaboration (including clusters, and public procurement). However, it is not clear if these instruments (at least those more innovative) are to be deployed during the implementation phase, or they were put in the strategies just because of the fashion or the recommendations made by Commission and other reference institutions at European and international level.

Figure 3: Regions in Spain by Type of Policy Instrument Included in the IS3 2014-2020

Regions by policy instruments

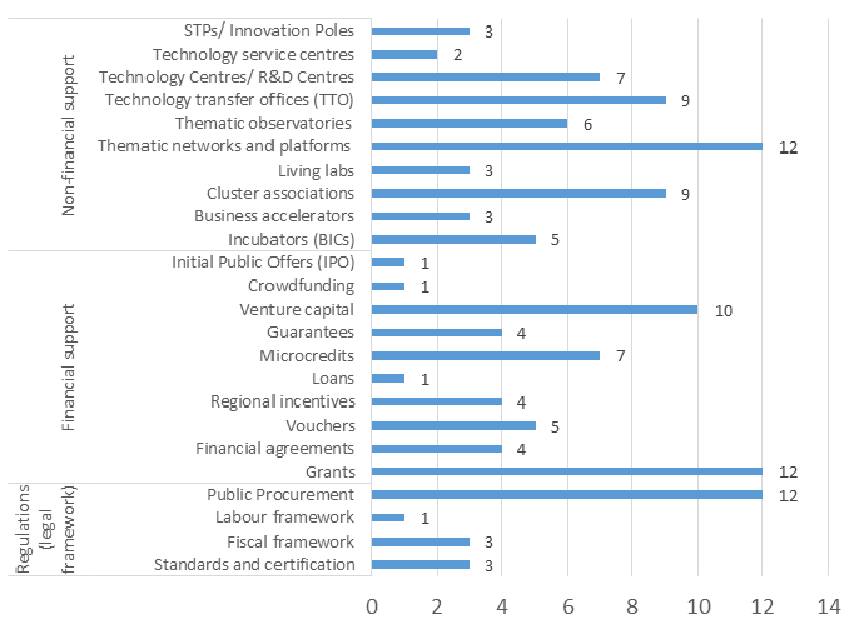

Policy instrument by region

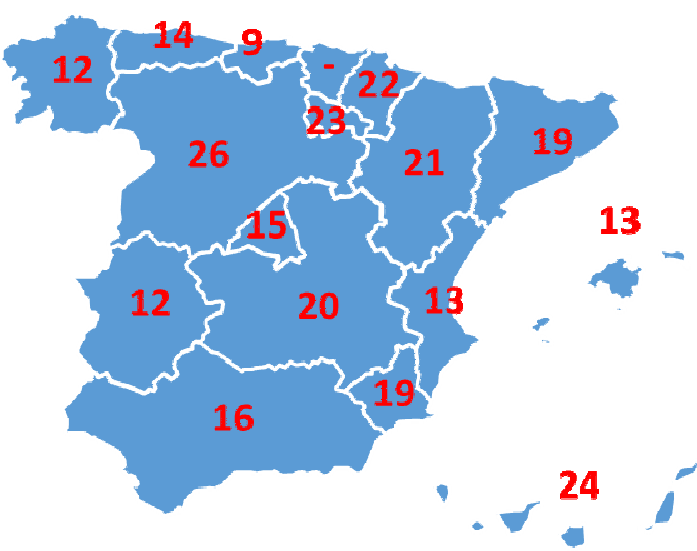


Finally, considering the number of instruments (financial, non-financial and legal frameworks) by region, some remarkable differences can be observed: some of RIS3 accounted for very limited number of instruments (less than 15) while others accounted for a wide ranch of measures covering virtually most of the policy spectrum available. In this sense, it is therefore logical to wait until the real implementation to assess the scope of this policy designs (more so when by the moment there is no a way to know the future availability of funds from ERDF to concrete the allocation of resources to those instruments.).

\subsection{The Measurement Exercises in RIS3: Indicators and Monitoring}

The third are to be analysed in the paper refers to the evaluation and monitoring elements to be included in RIS3. As Commission proposed (EC 2013) evaluation and monitoring systems in RIS3 may follow a set of recommendations regarding the quality of indicators, the foundations behind a logic of intervention (including the consideration of input, output and results indicators) and a participatory followup mechanisms for improving the strategy and its instruments. Besides, the importance of evaluation and monitoring has been consolidated also in the shape of becoming a general ex-ante condition for ERDF (not only for R\&D).

Del Castillo et al. (2015b) include a detailed analysis of the state of the art of evaluation and monitoring of Spanish RIS3 ${ }^{10}$. Main results of that research appear in Figure 4. It shows the mechanisms included in the RIS3 to make the monitoring during the period (and evaluation afterwards), the number of indicators by typology (context, output and results indicators) as well as the consideration of the logic of intervention within the overall evaluation and monitoring proposal.

Figure 4: Brief Summary of Monitoring end Evaluation Systems in Spanish RIS3

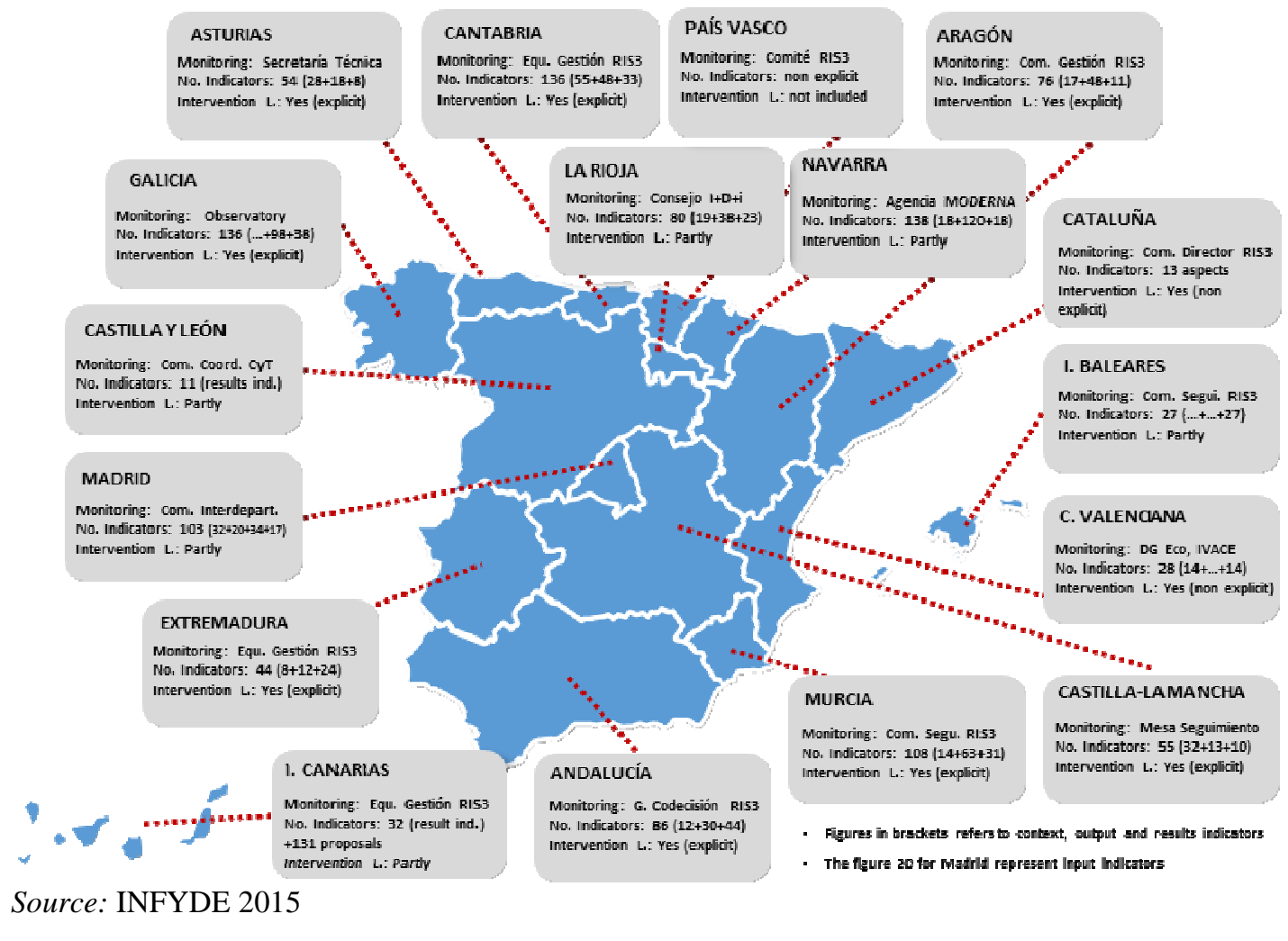


Main conclusions obtained from the analysis pointed out that Spanish RIS3 include a relative high number of indicators that may present difficulties in terms of gathering information during the monitoring process, and that not all strategies lay on a clear logic of intervention (causality not only between indicators, but between general objectives and specific policy measures.

More concretely, these are some of the conclusions of the analysis:

- A high number of indicators, with not always a clear division between input, output and result measures.

- A general extension of the intervention logic proposed by the Commission (at least in nominal terms) but a general lack of application in both policy levels (objectives-measures) and between indicators.

- An establishment of a formal body to follow-up the strategy, but a lack of concretion in terms of gathering and elaboration of recommendations to carry out improvements on both strategy and its action plan (at least in the documents published).

Nevertheless, RIS3 exercised can be considered as a step forward regarding the improvement of the mechanisms and guidelines on how to design and deploy real evaluation system to continuously improve the policy frameworks at regional level.

\section{Concluding Discussion}

Despite the great opportunity that supposes the smart specialization model and its strategic reflection, a series of limits were exposed in the paper. Among them, the existence of important methodological gaps (entrepreneurial discovery, mechanisms for effective and agreed priority setting, etc.) as well as the short deadline available due to the linkage between RIS3 and the ex-ante condition, may determine negatively the success of the strategy. In fact, the latter has pushed policymakers to understand a RIS3 as a mere milestone to reach the EU funding. Nevertheless, in both cases, this may result in a RIS3 and a strategic process not aligned nor adapted to specific regional reality.

The paper has analysed the state of the art in current Spanish RIS3 just to assess the scope of these potential threats within the real strategic definition exercises. Therefore, the Spanish experience has shown the following:

- Spanish RIS3 exercises shown a lax priority setting, that is, a higher number of specialised areas than what each regional economic structure may justify.

- It seems that potential lobbies or group of interest, as well as the risk aversive preferences of regional authorities, guides a wider selection of specialisation choices.

- On the contrary, current RIS3 processes included better methodologies for both identifying and gathering consensus about a limits set of areas of support.

- Even though entrepreneurial discoveries are in the core of the strategies (they are the way to achieve the mentioned specialised diversification) there was no real integration (or at least an operative one) of them. 
- Policy instruments and measures still lack on specific (and adapted) approaches to cover the specific need of sectors and innovation: they are not only rather horizontal but also quite traditional regarding past periods.

- Although evaluation and monitoring designing efforts have increased considerably, it still lacks on a coherent definition of indicators as well as a feasible ongoing improvement system.

All these points remark that RIS3 strategies are (or may be) the roadmaps to materialize specific public support schemes contributing to the goals of smart specialisation But they have to be understood as tools that need to be improved during all the life of their implementation.

The core of smart specialization lays in the radical innovations that arise from the creative combination of technologies and/or sectors.

A RIS3 should be able to establish mechanisms to identify/discover those radical innovations that through entrepreneurial discovery processes become initiatives, as well as the mechanisms to support and consolidate them.

From this perspective, a set of recommendation may be proposed taking in account the Spanish case, with an indicative and not an exhaustive aim:

- A progressive homogenization in the methods and mechanisms of stablishing priorities at regional level (that is, sharing common databases, sectorial/technological definitions, etc.).

- An establishment of a continuous forum to put together and discuss shared problems and difficulties, and initiate a learning process between regions in issues related to RIS3 (e.g. entrepreneurial discoveries, indicators and monitoring, interregional collaboration and synergies, etc. $)^{11}$.

- A deeper revision of the RIS3 strategies to identify critical parts to be improved, namely: the tuning of priority choices included, indicators to follow-up and improve the strategy, a data set of policies (some of which could be developed jointly by different regions), the open economy dimension of the strategies (e.g. collaboration potential with other Spanish regions but also through Europe).

- A reinforced effort in sensitizing and extending the idea and culture behind smart specialisation no only to regional authorities (policymakers) but to the whole spectrum of agents in the regional innovation system

- And last but not least, to have clear the idea that the RIS3 process is not about a punctual or an static document, but a process by which new territorial opportunities are discovered, fostered and supported.

\section{Bibliography}

Bellini, N. Teräs, J. and Ylinenpäá, H. (2012) Science and Technology Park in the Age of Open Innovation. The Finnish Case. Symphonya. Emerging Issues in Management (symphonya.unimib.it), n.1

http://dx.doi.org/10.4468/2012.1.03bellini.teras.ylinenpaa

Del Castillo, J. Paton, J. \& Barroeta, B. (2012). Smart specialisation Strategies RIS3: A quick guide. INFYDE Working papers, No. 5

Del Castillo, J. Paton, J., Barroeta, B. (2013a) Territorial Governance in a Smart Specialisation Context, Territorial Cohesion in Europe, Transdanubian Research Institute, 70th Aniversary 
Del Castillo, J. Paton, J., Barroeta, B. (2013b) Cluster and Entrepreneurial Discovery Strategies. Tools for RIS3. TCI International Conference

Del Castillo, J., Paton J., Barroeta, B. (2015a) Smart Specialisation and Entrepreneurial Discovery: Theory and Reality. The Portuguese Review of Regional Studies, 39

Del Castillo, J., Paton J., Barroeta, B. (2015b) Medición y Seguimiento para políticas de I+D+I en el nuevo periodo 2014-2020. INFYDE Working Papers, No. 10

Del Castillo, J. Paton, J. (2011) Methodology for Cluster Mapping and Impact Analysis. Identifying Critical Mass for Innovation. Journal of Business and Economics

Del Castillo, J., Paton, J. (2012) Entrepreneurial Discovery Process in the Basque Country: The Electric Vehicle Case. Bilbao. AECR Conference 2012.

European Commission (2002) Regional Innovation Strategies under the European Regional Development Fund Innovative Actions 2000-2002. DG Regional Policy.

European Commission (2009) Preparing for our Future: Developing a Common Strategy for key Enabling Technologies in the EU. COM(2009)512

European Commission (2011) Research and Innovation Strategies for Smart Specialisation: factsheet. Luxembourg: Office for Official Publications of the European Communities.

European Commission (2013) Regulation of the European Parliament and of the Council on Specific provisions concerning the ERDF and the Investment for growth and jobs goal" (EC) No 1013/2013

Foray, D. (2009a) Understanding Smart Specialisation. In Pontikakis, D., Kyriakou, D. \& Van Bavel, R. (eds.) The Questions of $R \& D$ Specialisation. Perspectives and policy implications. Luxembourg: Office for Official Publications of the European Communities.

Foray, D. (2009b) Structuring a Policy Response to a Grand Challenge. In Pontikakis, D., Kyriakou, D. \& Van Bavel, R. (eds.) The Questions of R\&D Specialisation. Perspectives and policy implications. Luxembourg: Office for Official Publications of the European Communities.

Foray, D.; David, P.A., Hall, B. (2009) Smart Specialisation - The Concept. Knowledge Economists Policy Brief 9, June 2009.

Frenken, K.; Van Oort, F.G., Verburg, T. (2007) Related variety, unrelated variety and regional economic growth. Regional Studies 41 (5): 685-97.

http://dx.doi.org/10.1080/00343400601120296

IPTS (2012) Guide to research and innovation strategies for smart specialisation RIS3

Ministry of Finance and Public Administration -MINHAP (2014) Spanish Partnership Agreement 2014-2020.

Mccann, P., Ortega-Argilés, R. (2011) Smart Specialisation, Regional Growth and Applications to EU Cohesion Policy. Economic Geography Working Paper 2011, Faculty of Spatial Sciences, University of Groningen.

OECD (2011) Regions and Innovation Policy OECD Reviews of Regional Innovation, OECD Publishing.

Pontikakis, Kyriakou, Van Bavel (2009) The Question of $R \& D$ Specialisation: Perspectives and Policy Implications. JRC Scientific and Technical Reports.

Paton, J., Barroeta. B. (2012) RIS3 Policy Typology: The Optimum Policy Mix for a Regional Smart Specialisation. Bilbao. 9th conference developments in Economic theory and policy EHU/Cambridge. June 2012.

Paton, J. (2013) Smart Specialisation and RIS3: a critical analysis

Paton, J. (2014) Los Clusters. Piezas clave de la economía del conocimiento. Tesis doctoral. Universidad del País Vasco

Porter, M.E. (2003) The Economic Performance of Regions. Regional Studies 37: 549-578 http://dx.doi.org/10.1080/0034340032000108688

Technopolis (2006) Strategic Evaluation on Innovation and the Knowledge Based Economy in Relation to the Structural and Cohesion Funds, for the Programming Period 2007-2013. Synthesis Report 


\section{Notes}

${ }^{1}$ S3 Platform: http://s3platform.jrc.ec.europa.eu/

2 http://s3platform.jrc.ec.europa.eu/guides

3 Some authors such as Bellini et al (2012) state that "the new emphasis on technological platform, related variety, smart specialisation, etc. is leading to a substantial (although still incomplete) revision of established frameworks"

${ }^{4}$ Most of Spanish regions have followed EC and S3 Platform guidelines since the beginning of the definition stage in 2011. Besides, all of them participated in the S3 Platform initiatives and workshops, the Spanish Network of R\&D+I policies has supported the regional efforts in RIS3 definition, and all the documents were published and included in the Spanish Partnership Agreement 2014-2020.

${ }^{5}$ And consequently RIS3 lacked from a systematic and homogeneous approach on entrepreneurial discovery inclusion

${ }^{6}$ The specialisation coefficient was a metric popularised by Porter (2003) when identifying cluster in US and Europe

${ }^{7}$ www.clusterobservatory.eu

${ }^{8}$ no differences between regions with urbanization economies from those characterized by specialisation economies

${ }^{9}$ Key Enabling Technologies known as nanotechnology, micro- and nanoelectronics including semiconductors, advanced materials, biotechnology and photonics. $\underline{\text { http://ec.europa.eu/enterprise/sectors/ict/key_technologies/index_en.htm }}$

${ }^{10}$ They include in the analysis a detailed breakdown of indicators by policy priorities as well as by policy instruments by region.

${ }^{11}$ Thta is the role that play in Spain the R\&D+I network supported by Spanish Government and DG Regio. 